\title{
Screening and Application of Phthalic Acid Degrading Bacteria
}

\author{
Wenhao Li ${ }^{*}$, Xiaoqiong Yang1*, Gaodong $\mathrm{Li}^{1}$, Cheng $\mathrm{Li}^{2}$, Yuhan $\mathrm{Xu}^{2}$, Jingguo Sun ${ }^{2}$, \\ Changjun Wang', Shunyi $\mathrm{Li}^{2}$, Xin $\mathrm{Ma}^{2}$, Qin Wang ${ }^{2}$, Shouwen Chen ${ }^{2}$, Jun Yu${ }^{2 \#}$, Yong Yang# \\ ${ }^{1}$ College of Life Sciences, Hubei University, Wuhan, China \\ ${ }^{2}$ Tobacco Research Institute of Hubei Province, Wuhan, China \\ Email: "80196867@qq.com, "519971800@qq.com
}

How to cite this paper: Li, W.H., Yang, X.Q., Li, G.D., Li, C., Xu, Y.H., Sun, J.G., Wang, C.J., Li, S.Y., Ma, X., Wang, Q., Chen, S.W., Yu, J. and Yang, Y. (2018) Screening and Application of Phthalic Acid Degrading Bacteria. Open Journal of Applied Sciences, 8, 586-597.

https://doi.org/10.4236/ojapps.2018.812047

Received: November 9, 2018

Accepted: December 17, 2018

Published: December 20, 2018

Copyright $\odot 2018$ by authors and Scientific Research Publishing Inc. This work is licensed under the Creative Commons Attribution International License (CC BY 4.0).

http://creativecommons.org/licenses/by/4.0/

\begin{abstract}
O-phthalic acid is a kind of important pollutant, which accumulates in the environment with the extensive use of plastics and other products. Meanwhile, phthalic acid is one of the high content of allelopathic autotoxic substances secreted by tobacco. The accumulation of phthalic acid in soil is an important cause of tobacco continuous cropping effect. In order to degrade phthalic acid accumulated in environment, the barrier effect of tobacco continuous cropping caused by phthalic acid accumulation in soil can be removed. A strain capable of degrading phthalic acid was isolated from sludge of sewage treatment plant and compared with 16 s DNA. The homology between this strain and Enterobacter sp. is $99 \%$. The optimum growth conditions are as follows: $\mathrm{pH} 7$ at $30^{\circ} \mathrm{C}, 500 \mathrm{mg} / \mathrm{L}$ of o-phthalic acid, inoculation concentration $\geq 1.2 \%$ and its highest degradation rate of o-phthalic acid is $74 \%$. The results of pot experiment showed that the degradation efficiency of o-phthalic acid in soil was about $40 \%$, which alleviated the inhibitory effect of o-phthalic acid accumulation on tobacco growth.
\end{abstract}

\section{Keywords}

O-Phthalic Acid, Allelopathic Autotoxic Substance, Tobacco

\section{Introduction}

O-phthalic acid is the main raw material for the production of phthalic acid ester plasticizer [1], phthalic acid and its product, phthalate (PAEs) [2], have penetrated into food, medicine, human body, food bottle packaging products, Water bodies and terrestrial ecosystems [3] have caused great harm to ecosystem and

*These authors contributed equally to this work.

\#Corresponding authors. 
human health, and have been regarded as universal pollutants all over the world. Studies have shown that phthalic acid and its derivatives are also the main allelopathic autotoxic substances that cause continuous cropping barriers of tobacco, soybean, maize and other important economic plants [4], and are also important substances [5] [6] for synergistic soil-borne diseases and insect pests which caused serious economic losses [7]. The elimination of phthalic acid and its esters from phthalic acid derivatives to the environment, human beings and crops has attracted great attention in related research fields [8]. Methods of eliminating phthalic acid and its esters mainly contained physical [9], chemical [10] and biological methods [11]. At the same time, it is limited to the treatment of phthalic acid and its esters in industrial wastewater and has not been widely used [12]. However, biological methods, especially the microbial degradation of phthalic acid and its esters, have attracted much attention [13]. Phthalates are first hydrolyzed to phthalate monoesters and then hydrolyzed to phthalic acid in microorganisms. Finally it was degraded into organic acids to provide nutrients for microbes [14]. Therefore, microbial degradation of phthalic acid is characterized by high efficiency, low cost and environmental friendliness [15].

Screening or domesticating PAEs (phthalic acid esters) degradation strains from the environment is the most simple and economical way [16] [17]. Presently, the main high-efficient degrading bacteria are Arthrobacter sp., Pseudomonas sp. and Pseudomonas sp. etc. [18] [19]. All of these single bacteria have defects such as single substrate, incomplete degradation and so on [20]. Although the microbe consortia overcame the sole defect of substrate and the degradation efficiency were improved to a certain extent [21]. However, most of the studies focused on the degradation of phthalic acid esters, but underestimated the degradation of phthalic acid [22], probably due to the high content of phthalic acid in soil [23]. Additionally, most of the previous studies were limited to shaking flask experiment in laboratory, and there were few reports on whether biodegrading bacteria could still worked in soil environment. Moreover, microbes in soil environment are regarded as the largest biological diversity pool in nature [18], which contains more efficient microbes degraded phthalic acid and its esters.

Based on the above reasons, the biodegradation efficiency of phthalic acid in soil was tested by screening high efficiency phthalic acid degrading bacteria which could play an important role in soil environment, and the relationship between degradation bacteria and physiological index of tobacco was analyzed. It provides valuable information for the discussion of the mechanism of continuous cropping barrier and the prevention and control of soil-borne diseases in cash crops such as tobacco.

\section{Materials and Methods}

\subsection{Screening and Identification of Bacteria}

\subsubsection{Sources and Medium of Bacteria}

$20 \mathrm{~g}$ of silt collected from the sewage treatment pool of Shahu Lake in Wuhan 
City and the sewage outlet of Chemistry and Chemical Engineering College, Hubei University. The sludge was stored in the sterilized $250 \mathrm{~mL}$ triangle bottle and stored in $-4^{\circ} \mathrm{C}$ refrigerator.

Basic salt medium containing (g/L): $\left(\mathrm{NH}_{4}\right)_{2} \mathrm{SO}_{4} 2.0, \mathrm{MgSO}_{4} 0.2, \mathrm{CaCl}_{2} \cdot 2 \mathrm{H}_{2} \mathrm{O}$ $0.01, \mathrm{FeSO}_{4} 0.001, \mathrm{Na}_{2} \mathrm{HPO}_{4} \cdot 12 \mathrm{H}_{2} \mathrm{O} 1.5, \mathrm{KH}_{2} \mathrm{PO}_{4} 0.5, \mathrm{KH}_{2} \mathrm{PO}_{4}$ 1.5; Luria-Bertani (LB) medium containing $(\mathrm{g} / \mathrm{L}): \mathrm{NaCl} 10$, yeast powder 5, peptone 10; Potato Dextrose Agar (PDA) medium containing (g/L): potato filtrate 200, glucose 20; Kos 1 medium containing (g/L): soluble starch 20, $\mathrm{NaCl} 0.5, \mathrm{KNO}_{3} 1, \mathrm{~K}_{2} \mathrm{HPO}_{4} \cdot 3 \mathrm{H}_{2} \mathrm{O}$ $0.5, \mathrm{MgSO}_{4} \cdot 7 \mathrm{H}_{2} \mathrm{O} 0.5, \mathrm{FeSO}_{4} \cdot 7 \mathrm{H}_{2} \mathrm{O} 0.01$; Beef extract peptone medium (BEPM) containing $(\mathrm{g} / \mathrm{L})$ : beef extract 3 , peptone $10, \mathrm{NaCl} 5 \mathrm{~g}$; Bengal red medium containing (g/L): peptone 5, glucose 10, $\mathrm{KH}_{2} \mathrm{PO}_{4} 1, \mathrm{MgSO}_{4}$ 0.5, Bengal red 0.03, chloramphenicol 0.1 .

\subsubsection{Enrichment and Screening of Phthalic Acid Degradation Strain}

$10 \mathrm{~g}$ silt was placed in the sterilizing triangle flask which contained $100 \mathrm{~mL}$ basic medium, and cultured in $30^{\circ} \mathrm{C}$ of $180 \mathrm{r} / \mathrm{min}$ orbital incubator overnight. And then $10 \mathrm{~mL}$ suspension was added to the $90 \mathrm{~mL}$ BEPM medium for enrichment, and the domestication was done by gradient pressure culture method. The concentration of phthalic acid in enrichment medium was gradually increased from $100 \mathrm{mg} / \mathrm{L}$ to $700 \mathrm{mg} / \mathrm{L}$. A solid BEPM medium containing $500 \mathrm{mg} / \mathrm{L}$ phthalic acid was used to isolate the tolerant bacteria by dilution and coating plate method. The colony with good growth, clear colony and distinct morphology was selected, and a single colony was isolated by plate marking method. The isolated colony was phthalic acid tolerant bacteria.

\subsubsection{Species Identification}

A strain of bacterium that can specifically degrade phthalic acid was selected from the tolerant bacteria. Physiological and biochemical identification of bacteria referred to the "Berger's systematic bacteriology manual" 9th edition. Molecular biological identification was carried out according to the following procedures: the strain was cultured on LB medium for $8 \mathrm{~h}$, bacterium suspension was made by pick bacterium into $100 \mu \mathrm{L}$ solution in $1.5 \mathrm{ml} \mathrm{EP}$ tube, and 12,000 $\mathrm{r} / \mathrm{min}$ centrifuged for $2 \mathrm{~min}$ after $15 \mathrm{~min}$ of boiling water bath. The supernatant was isolated as a template for 16SDNA amplification and PCR amplification and the PCR reaction system was as follows: DNA template $5 \mu \mathrm{L}$, forward and reverse primer each $1 \mu \mathrm{L}$ respectively, dNTP $(10 \mathrm{mmol} / \mathrm{l}) 1 \mu \mathrm{L}, 10 \times$ Extaq buffer 5 $\mu \mathrm{L}$, Extaq $1 \mu \mathrm{L}$, supplemented with double distilled water to $50 \mu \mathrm{L}$. The primer sequence was: 27F: 5'-AGAGTTTCCTGCTCAG-3'; 1492R:

5'-GTTACCTTACGACTT-3'; Amplification procedure: predenaturation at $94^{\circ} \mathrm{C}$ for $3 \mathrm{~min}, 94^{\circ} \mathrm{C}$ denaturation for $1 \mathrm{~min}, 61^{\circ} \mathrm{C}$ annealing for $1 \mathrm{~min}, 72^{\circ} \mathrm{C}$ extension for $1 \mathrm{~min}$, set $30 \mathrm{cycles}$ and at the end of procedure set $72^{\circ} \mathrm{C}$ extension for 5 min, $4^{\circ} \mathrm{C}$ preservation for $30 \mathrm{~min} .0 .8 \%$ agarose gel electrophoresis to detect PCR products. The size of the amplified product was about $1450 \mathrm{bp}$, and sequenced by Wuhan Qingke Biological Company. The 16s DNA sequence results was blast in GenBank. 


\subsection{Culture Condition Optimization}

The growth of Enterobacter sp. $\mathrm{NO}_{3}$ was affected by different parameters and single factor experiments were designed. The single colony of Enterobacter sp. $\mathrm{NO}_{3}$ was inoculated in LB medium and cultured overnight. After collected by refrigerated centrifuge at $5000 \mathrm{rpm}$ for $2 \mathrm{~min}$, the bacteria were resuspended in inorganic salt medium, and the value of OD600 was adjusted to 1 , which was used as seed. Seed was inoculated in $50 \mathrm{~mL}$ basic salt medium containing 500 $\mathrm{mg} / \mathrm{L}$ phthalic acid (except phthalic acid concentration test), and different culture temperatures $\left(18^{\circ} \mathrm{C}, 30^{\circ} \mathrm{C}, 37^{\circ} \mathrm{C}, 45^{\circ} \mathrm{C}\right), \mathrm{pH}(4,5,6,7,8,9)$ and inoculation concentration $(0.4 \%, 0.8 \%, 1.2 \%, 1.6 \%$ and $2.0 \%)$ were set respectively. After those parameters were optimized, different concentration of phthalic acid (100 $1000 \mathrm{mg} / \mathrm{L}$ ) experiment were set. OD600 was measured at $48 \mathrm{~h}$ after culture while the effect of inoculation concentration on growth was measured every $8 \mathrm{~h}$. The experimental data were repeated 3 times and averaged.

\subsection{Effect of Degradation Rate and Different Conditions on Degradation Efficiency}

The effects of different conditions on the ability of Enterobacter sp. $\mathrm{NO}_{3}$ to degrade phthalic acid were detected by liquid chromatography under the conditions mentioned in 2.2. The supernatant was gathered by 12,000 r/min centrifugation for $5 \mathrm{~min}$. After the supernatant was extracted by the same amount of ethyl acetate, the extract was evaporated to crystallization by rotating evaporator, and then dissolved in aseptic water and filtered by $0.22 \mu \mathrm{m}$ organic filter membrane. The content of phthalic acid was determined by high performance liquid chromatography (HLPC). The chromatographic conditions were as follows: Agilent ZORBAX SB-Aq (250 $\mathrm{mm} \times 4.6 \mathrm{~mm})$; mobile phase: $\left.5 \mathrm{mmol} / \mathrm{L}_{2} \mathrm{SO}_{4}\right)$, flow rate: $500 \mu \mathrm{L} / \mathrm{min}$, sample volume $20 \mu \mathrm{L}$.

\subsection{Effect of Degrading Bacteria on the Growth of Tobacco Seedling}

After transplanting tobacco seedlings, set experimental group 1 irrigated with 50 $\mathrm{mL}$ phthalic acid solution $(2 \mathrm{~g} / \mathrm{L})$ and Enterobacter sp. $\mathrm{NO}_{3}$ bacterial solution 5 $\mathrm{mL}\left(0.3 \times 10^{9} \mathrm{CFU} / \mathrm{mL}\right)$, set experimental group 2 with $50 \mathrm{~mL}$ phthalic acid solution $(2 \mathrm{~g} / \mathrm{L})$ and water $5 \mathrm{~mL}$, and set control group with $55 \mathrm{~mL}$ water. The plant height, stem diameter, fresh weight and dry weight of rhizome and leaf were measured after cultured in constant temperature and humidity greenhouse for four weeks. Each group has 10 pots of tobacco seedlings and the experimental data were repeated 3 times and averaged.

\subsection{Detection of Degradation Effect of Degrading Bacteria in Soil}

In order to study the degradation effect of Enterobacter sp. $\mathrm{NO}_{3}$ on phthalic acid under the condition of soil source, the content of phthalic acid was determined by high performance liquid chromatography (HLPC) after filtration. The liquid chromatographic conditions are the same as 2.3. 


\subsection{Data Statistics and Analysis}

Data processing and analysis using origin 8.5.

\section{Results and Discussion}

\subsection{Screening and Identification of Strains}

\subsubsection{Main Physiological and Biochemical Characteristics of Enterobacter $\mathrm{sp} \mathrm{NO}_{3}$}

The colony of strain $\mathrm{NO}_{3}$ present characteristics like milky white, translucent, round, smooth, regular in edge and flat in colony. Gram-stained bacteria were rod shaped and Gram-negative bacteria.

The physiological and biochemical characteristics of strain NO3 are described in Table 1.

\subsubsection{SDNA Identification Results}

The DNA sequence of the 16S RNA region of the strain NO3 was obtained and the length of the product was $1466 \mathrm{bp}$. The blasted results in NCBI and the distance tree revealed that it was close to Enterobacter sp. 3-1t (EU543690.1) and Enterobacter sp. E4M-P (GQ478269.1). The homology was 99\% (Figure 1), the microbe was therefore inferred to be Enterobacter $s p$., and the strain was named Enterobacter sp. $\mathrm{NO}_{3}$, deposited in GenBank (GenBank: MK128455.1).

Table 1. Main physiological and biochemical characteristics of strain $\mathrm{NO}_{3}$.

\begin{tabular}{cccc}
\hline Gram stain & - & Sucrose & - \\
Glucose & + & D-Fructose & + \\
D-Galactose & + & Trehalose & - \\
L-Arabinose & + & mannose & + \\
maltose & - & D-Xylose & - \\
D-Ribose & - & Rhamnose & + \\
Sorbitol & - & Sarcosine & + \\
Mannitol & - & Casein & + \\
Ethanol & - & Ammonia Production & + \\
D-Malate & + & Cellulose Decompose & + \\
Citraconate & + & Lecithin Enzyme & + \\
D-Alanine & + & Starch Hydrolysis & + \\
D-Tryptophan & + & Gelatine Liquefication & - \\
D-Tartrate & - & V-P Test & - \\
Glycolate & - & Denitrification & + \\
Pantothenate & & & + \\
\hline
\end{tabular}

Note: + positive, -negative 


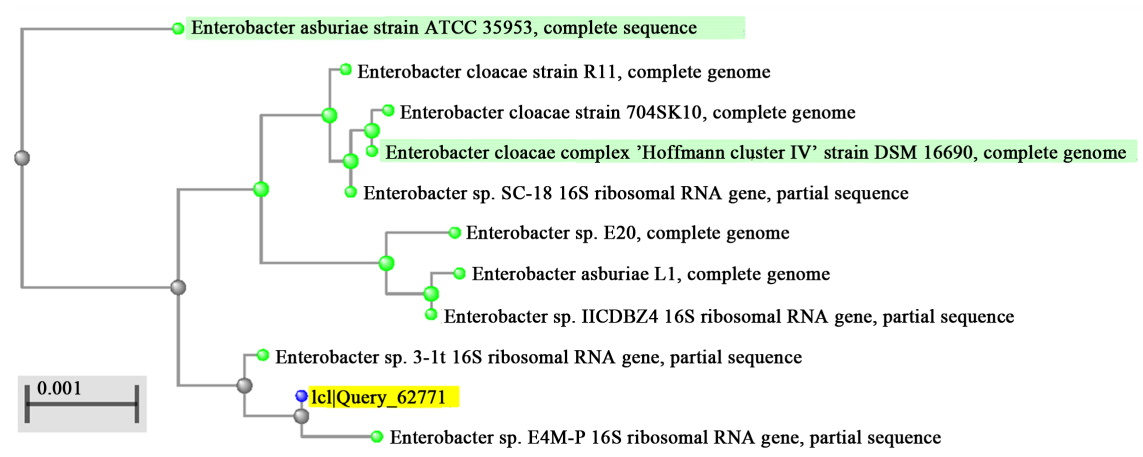

Figure 1. Phylogenetic tree.

\subsection{Culture Condition Optimization}

The common factors related to growth are $\mathrm{pH}$, temperature, inoculums concentration and substrate concentration. The effect of cultured $\mathrm{pH}$ on the growth of Enterobacter sp. $\mathrm{NO}_{3}$ was shown in Figure 2(a). Enterobacter sp. $\mathrm{NO}_{3}$ could tolerance $\mathrm{pH} 4.0$ to 9.0 and its most optimum $\mathrm{pH}$ was 7.0. As Figure 2(b) had shown, when the concentration of phthalic acid was $500 \mathrm{mg} / \mathrm{L}$, the growth of Enterobacter sp. $\mathrm{NO}_{3}$ was the highest. Figure 2(c) represented the effect of culture temperature on the growth of Enterobacter $\mathrm{sp} . \mathrm{NO}_{3}$, its suitable temperature range was $30^{\circ} \mathrm{C}-37^{\circ} \mathrm{C}$, the growth of Enterobacter sp. $\mathrm{NO}_{3}$ was inhibited while the temperature was below $30^{\circ} \mathrm{C}$ or above $37^{\circ} \mathrm{C}$. The effect of inoculation concentration on the growth of the strain $\mathrm{NO}_{3}$ also had been tested, the inoculation amount had no effect on the growth of Enterobacter sp. $\mathrm{NO}_{3}$ when the inoculation concentration was greater than or equal to 1.2 which had been showed in Figure 2(d). When the inoculation amount was less than 1.2, the growth was inhibited 72 hours before inoculation. Effects disappear after 72 hours.

\subsection{Degradation Efficiency Factors of Phthalic Acid}

The effect of cultured $\mathrm{pH}$ on the degradation efficiency of Enterobacter sp. $\mathrm{NO}_{3}$ was shown in Figure 3(a). When the medium pH was 7.0, the degradation efficiency was the highest, and the effect of initial phthalic acid concentration on the degradation efficiency of Enterobacter sp. $\mathrm{NO}_{3}$ was shown in Figure 3(b). When the concentration of phthalic acid is $500 \mathrm{mg} / \mathrm{L}$, the degradation efficiency is the highest, and the effect of temperature on the degradation efficiency of Enterobacter sp. $\mathrm{NO}_{3}$ is shown in Figure $3(\mathrm{c})$. When the temperature is $30^{\circ} \mathrm{C}$, the degradation efficiency of Enterobacter sp. $\mathrm{NO}_{3}$ is the highest. Under the conditions of $\mathrm{pH} 7$, culture temperature $30^{\circ} \mathrm{C}$, initial concentration of phthalic acid 500 $\mathrm{mg} / \mathrm{L}$, inoculum $=1.2 \%$, and shaking flask culture for 7 days, the maximum degradation rate of phthalic acid to phthalic acid by Enterobacter sp. $\mathrm{NO}_{3}$ can be detected to be $74 \%$.

\subsection{Detection of Degradation Effect of Degrading Bacteria in Soil}

The degradation rate of phthalic acid in soil was detected by liquid chromatography. The peak area of HLPC was 913487 and $3376 \mathrm{mAu}^{*}$ s respectively under 


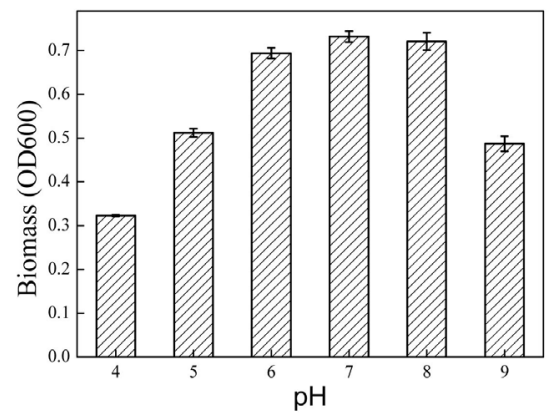

(a)

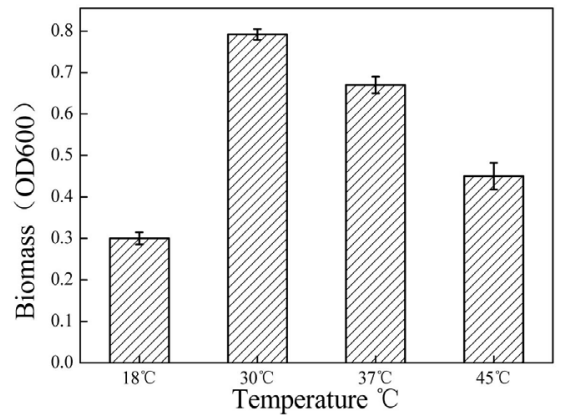

(c)

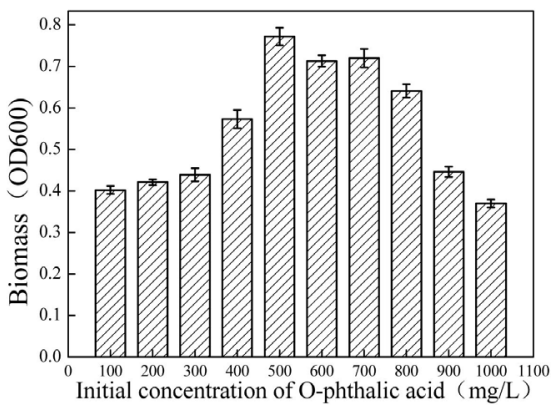

(b)

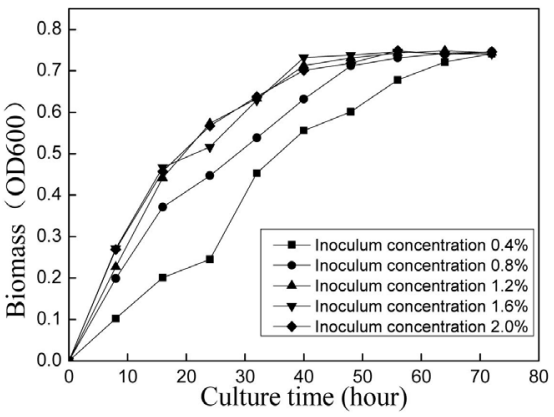

(d)

Figure 2. Effects of different culture conditions on Enterobacter sp. $\mathrm{NO}_{3}$ growth: $\mathrm{pH}$ value (a); initial concentration of O-phthalic acid (b); temperatures (c); inoculums concentration $(\mathrm{d})$.

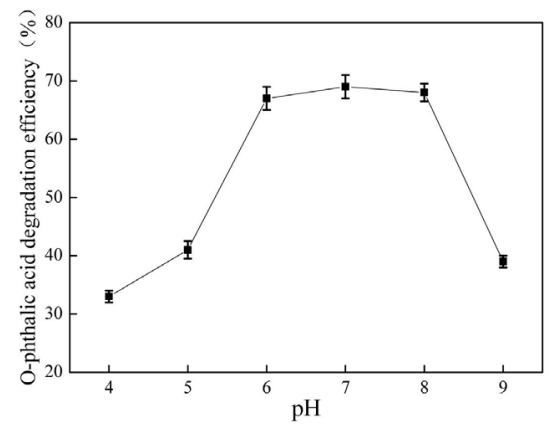

(a)

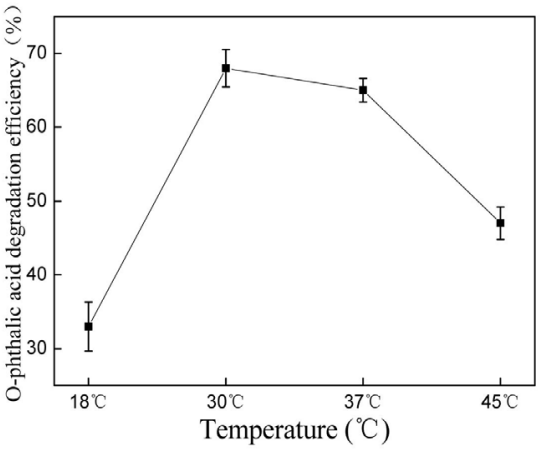

(c)

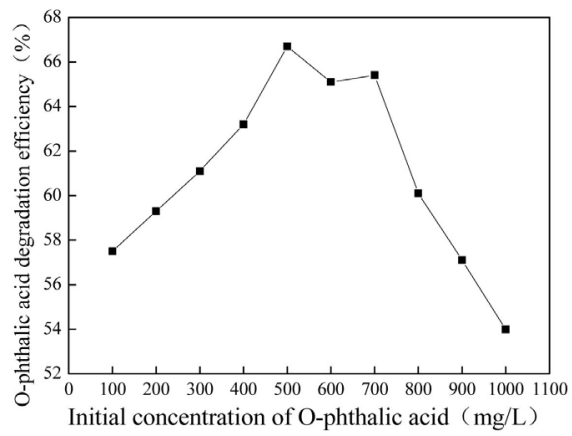

(b)

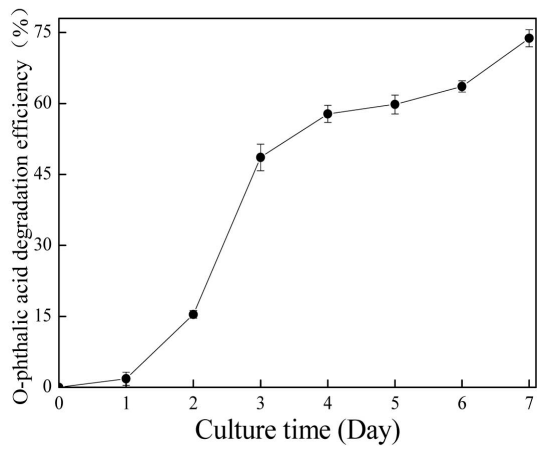

(d)

Figure 3. Effects of different culture conditions on the degradation efficiency of phthalic acid by Enterobacter sp. $\mathrm{NO}_{3}$. 
the condition of control, the peak area of the peak was 913487 and $3376 \mathrm{mAu}^{*} \mathrm{~s}$, respectively (Figure 4), under the condition of phthalic acid and phthalic acid degrading bacteria, the degradation rate of phthalic acid in soil was determined by liquid chromatography. Enterobacter sp. $\mathrm{NO}_{3}$ can still be degraded in soil in situ.

\subsection{Effect of Degrading Bacteria on the Growth of Tobacco Seedling}

Under the condition of Phthalic acid and phthalic acid degrading bacteria, there was significant difference in tobacco growth after 1 month of tobacco growth (Figure 5). The measured plant height values were $158.15 \pm 64.91109 .67 \pm 27.07$ and $150.17 \pm 76.50 \mathrm{~mm}$, respectively. The diameter of tobacco stem was $9.01 \pm$ $1.54 \pm 0.59$ and $9.12 \pm 2.28 \mathrm{~mm}$; , respectively. The mean fresh weight of leaf and rhizome of blank $(\mathrm{CK})$ was $6.83 \pm 1.02 \mathrm{U} 9.5 \pm 1.67$ and $34.67 \pm 4.51 \mathrm{~g}$, respectively, and the mean fresh weight of roots and leaves of Phthalic acid was $7.33 \pm$ $0.405 .33 \pm 0.87$ and $28.33 \pm 2.08$ g respectively. The mean fresh weight of mycorrhizal stem and leaf for phthalic acid degradation was $15.67 \pm 2.149 .67 \pm 1.35$ and $35.83 \pm 6.07$ g respectively.

The average dry weight of root stem and leaf of blank (CK) were $4.64 \pm 0.61 \pm$ 1.44 and $59 \pm 1.95 \mathrm{~g}$, the fresh weight of roots and leaves of phthalic acid were $4.16 \pm 0.31,2.27 \pm 0.25$ and $11.67 \pm 0.58 \mathrm{~g}$, respectively. The mean fresh weight of Phthalic acid degrading mycorrhizal stem and leaf was $7.08 \pm 0.31 \pm 3.61 \pm$ 0.97 and $13.69 \pm 0.59 \mathrm{~g}$ (Table 2).

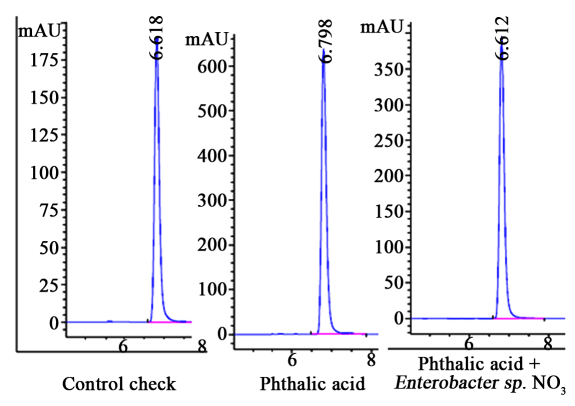

(a)

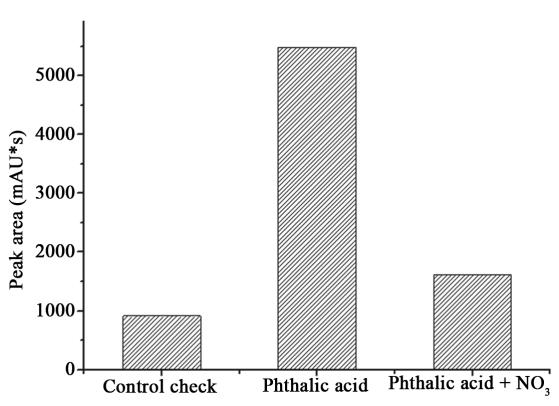

(b)

Figure 4. Degradation effect of phthalic acid in soil. (a) Peak time and retention time of high performance liquid phase; (b) Statistical results of peak area of degradation effect of phthalic acid.

Table 2. Physiological indexes of tobacco growth under different conditions $(n=90)$.

\begin{tabular}{ccccccccc}
\hline & Stem height $^{*}$ & Stem diameter & \multicolumn{2}{c}{ Fresh weight } & & \multicolumn{2}{c}{ Dry weight $^{*}$} \\
\hline Control check & $158.15 \pm 64.91$ & $9.01 \pm 1.54$ & $6.83 \pm 1.02^{\mathrm{a}}$ & $9.5 \pm 1.67^{\mathrm{b}}$ & $34.67 \pm 4.51^{\mathrm{c}}$ & $4.64 \pm 0.61^{\mathrm{a}}$ & $3.24 \pm 1.44^{\mathrm{b}}$ & $12.59 \pm 1.95^{\mathrm{c}}$ \\
O-phthalic acid & $109.67 \pm 27.07$ & $8.50 \pm 0.59$ & $7.33 \pm 0.40$ & $5.33 \pm 0.87$ & $28.33 \pm 2.08$ & $4.16 \pm 0.31$ & $2.27 \pm 0.25$ & $11.67 \pm 0.58$ \\
$\begin{array}{c}\text { O-phthalic acid }+ \\
\text { Enterobacter } \mathrm{sp} . \mathrm{NO}_{3}\end{array}$ & $150.17 \pm 76.50$ & $9.12 \pm 2.28$ & $15.67 \pm 2.14$ & $9.67 \pm 1.35$ & $35.83 \pm 6.07$ & $7.08 \pm 0.31$ & $3.61 \pm 0.97$ & $13.69 \pm 0.59$ \\
\hline
\end{tabular}

${ }^{n}$ is the total number of tobacco seedlings sampled in the experiment; ${ }^{*}$ unit: $\mathrm{mm} ;{ }^{\sharp}$ unit: $\mathrm{g} ;{ }^{\mathrm{a}, \mathrm{b}, \mathrm{c}}$ represents root, stem and leaf, respectively. 


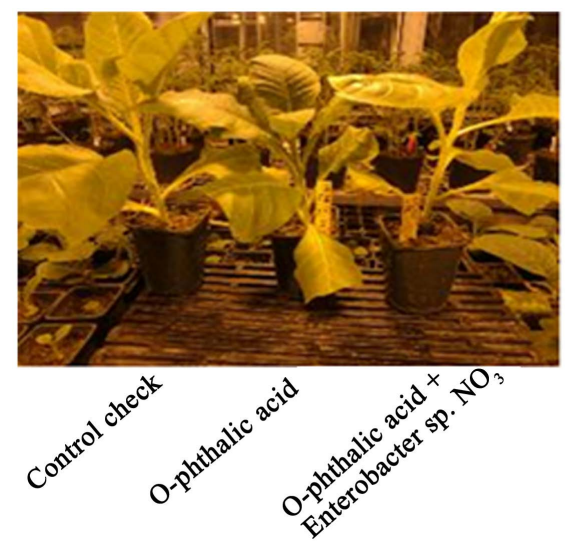

Figure 5. Phthalic acid and its degradation bacteria in pot culture.

\section{Discussion}

The pollution of phthalic acid and its derivatives to the environment has caused great attention at home and abroad [1] [2] [3], phthalic acid and its derivatives to tobacco, soybean. The effects of continuous cropping barriers and soil diseases on important cash crops such as maize have attracted much attention [4] [5] [6]. Using microbial degradation to eliminate the harm of phthalic acid and its derivatives is the most efficient, low-cost and environment-friendly approach in biological methods [15]. In this study, Phthalic acid degrading strains were screened from sludge of sewage treatment plant. The bacteria were identified as Enterobacterium by 16SDNA comparison analysis and named Enterobacter sp. $\mathrm{NO}_{3}$ (Figure 1). The optimum growth temperature is $30^{\circ} \mathrm{C}$ and the initial concentration of $\mathrm{pH}=7$, the initial concentration of phthalic acid was $500 \mathrm{mg} / \mathrm{L}$, inoculation dose was $1.2 \%$ (Figure 2).

The strain Enterobacter sp. $\mathrm{NO}_{3}$ selected in this paper belongs to a new type of bacteria, which is similar to the previously studied strains such as (Arthrobacter sp.), pseudomonas (Pseudomonas sp.). The degradation efficiency of this strain was 74 under the condition of shaking flask in laboratory, which was higher than that of other single strains [18] [21] [22]. The degradation efficiency of the strain was related to the temperature, $\mathrm{PH}$ value and the concentration of phthalic acid. The degradation efficiency of the strain was the highest at $30^{\circ} \mathrm{C}$, and the low concentration of phthalic acid promoted the degradation of the strain. The high concentration of phthalic acid could inhibit the degradation of the strain (Figure 3). The content of phthalic acid in soil environment is higher than that of phthalic acid derivative [23]. In this study, the degradation ability of phthalic acid was studied. The degradation rate of phthalic acid in soil was detected by liquid chromatography. Compared with blank control, the strain did not completely degrade phthalic acid, but compared with high concentration of phthalic acid in soil. The content of phthalic acid decreased by about $40 \%$ (Figure 4). The results showed that Enterobacter sp. $\mathrm{NO}_{3}$ could still be degraded in soil in situ. The results of physiological index measurement of tobacco seedling growth showed that the average height of tobacco was $158.15 \mathrm{~mm}, 109.67 \mathrm{~mm}$ and 
$150.17 \mathrm{~mm}$; under the condition of phthalic acid (Enterobacter sp. $\mathrm{NO}_{3}$ ) and phthalic acid (Enterobacter sp. $\mathrm{NO}_{3}$ ), respectively. The average wet weight and dry weight were $13.66 \mathrm{~g}$ and $20.39 \mathrm{~g}, 6.82 \mathrm{~g}, 6.03 \mathrm{~g}$ and $8.12 \mathrm{~g}$, respectively.

It has been proved that phthalic acid has the effect of causing crop continuous cropping obstacle [7] [24] and synergistic effect of soil-borne diseases and insect pests [5] [6]. The results of our study show that phthalic acid inhibits tobacco growth. The inhibitory effect of phthalic acid on tobacco was obviously alleviated by adding degrading bacteria. In addition, the growth effect of phthalic acid degradation was not obvious, but the weight index analysis showed that the effect of phthalic acid degradation bacteria on tobacco leaf growth was obvious. The results provide new information for the prevention of tobacco continuous cropping barriers, but whether degradation of phthalic acid can alleviate the occurrence of soil-borne diseases needs further study.

\section{Acknowledgements}

This work was supported by the key technology projects of China National Tobacco Corporation (CNTC) under Contract No. 110201502014 and No. 110201502018, and the key technology projects of Hubei tobacco companies under Contract No. 027Y2014-013.

\section{Conflicts of Interest}

The authors declare no conflicts of interest regarding the publication of this paper.

\section{References}

[1] Zhang, S.G. (1992) Technic Handbook of Fine Organic Chemicals. Science Press, Beijing, 1297.

[2] Li, X.M., Wang, J., Zhang, Q.H. and Li, H.M. (2015) Advances on the Development of Detection Methods for the Phthalate Esters in Food. Chinese Journal of Chromatography, 33, 1147. https://doi.org/10.3724/SP.J.1123.2015.06027

[3] Lu, S.H., Cai, S.S. and Cheng, S. (2017) Determination of 18 Phthalate Esters in Powder of Microencapsuiated Oil by Gas Chromatography-Mass Spectrometer. China Food Additives, 12, 182-191.

[4] Feng, D., Wang, X.Y. and Gao, Z.H. (2011) Causes and Control Measures of Continuous Cropping Obstacle in Horticultural Crops. Acta Agriculturae Jiangxi.

[5] Ju, H.Y., Han, L.M., Wang, S.Q. and Cong, D.L. (2002) Allelopathic Effect of Root Exudates on Pathogenic Fungi of Root Rot in Continuous Cropping Soybean. Chinese Journal of Applied Ecology, 13, 723-727.

[6] Lu, W.G., Zhang, C.L. and Yuan, F. (2002) Mechanism of Allelochemicals Inhibiting Continuous Cropping Cucumber Growth. Scientia Agricultura Sinica, 35, 106-109.

[7] Wang, F., Li, S.G., Xu, F.H. and Gu, J.G. (2013) The Research Progress on Mechanism of Continuous Cropping Obstacle. Soils and Fertilizers Sciences in China, 5, 6-13.

[8] Shen, P.P, Wang, Y.Y. and Gu, J.D. (2004) Degradation of Phthalic Acid and Or- 
tho-Dimethyl Phthalate Ester by Bacteria Isolated from Sewage Sludge and Its Biochemical Pathway. Chinese Journal of Applied \& Environmental Biology, 10, 643-646.

[9] Liu, J., Wang, K., Jia, R. and Wang, Z. (2003) Removal of Phthalate Esters from Drinking Water Using Ozone-Gac Process. Chinese Journal of Environmental Science, 24, 77-80.

[10] He, L., Gielen, G., Bolan, N.S., et al. (2015) Contamination and Remediation of Phthalic acid Esters in Agricultural Soils in China: A Review. Agronomy for Sustainable Development, 35, 519-534. https://doi.org/10.1007/s13593-014-0270-1

[11] Abdel Daiem, M.M., Rivera-Utrilla, J., Ocampo-Pérez, R., et al. (2012) Environmental Impact of Phthalic Acid Esters and Their Removal from Water and Sediments by Different Technologies-A Review. Journal of Environmental Management, 109, 164-178. https://doi.org/10.1016/j.jenvman.2012.05.014

[12] Chen, J.A., Qiu, Z.Q., Shu, W.Q. and Cao, J. (2007) Pollution of PAEs in Water and the Biodegradations Studies in China. Carcinogenesis, Teratogenesis \& Mutagenesis, 19, 212-214.

[13] Wen, Z.D., Gao, D.W. and Wu, W.M. (2014) Biodegradation and Kinetic Analysis of Phthalates by an Arthrobacter, Strain Isolated from Constructed Wetland Soil. Applied Microbiology and Biotechnology, 98, 4683-4690. https://doi.org/10.1007/s00253-014-5568-Z

[14] Huang, Y., Bian, Z.Q. and Tian, X.H. (2010) Progress of Degradation Techniques of Environmental Phthalic Acid Esters. Journal of Environment and Health, 27, 654-657.

[15] Singh, N., Dalal, V. and Mahto, J.K. (2017) Biodegradation of Phthalic Acid Esters (PAEs) and in Silico Structural Characterization of Mono-2-Ethylhexyl Phthalate (MEHP) Hydrolase on the Basis of Close Structural Homolog. Journal of Hazardous Materials, 338. https://doi.org/10.1016/j.jhazmat.2017.04.055

[16] Huang, M., Ma, Y., Wang, Y., Wan, J. and Zhang, H. (2010) Fate of Di-n-butyl Phthalate in a Laboratory-Scale Anaerobic/Anoxic/Oxic Wastewater Treatment Process. Bioresource Technology, 101, 7767-7772. https://doi.org/10.1016/j.biortech.2010.05.028

[17] Prasad, B. and Suresh, S. (2012) Biodegradation of Phthalate Esters by Variovorax sp. Apcbee Procedia, 1, 16-21. https://doi.org/10.1016/j.apcbee.2012.03.004

[18] Yang, C.F., Wang, C.C. and Chen, C.H. (2014) Di-n-butyl Phthalate Removal by Strain Deinococcus, sp. $\mathrm{r} 5$ in Batch Reactors. International Biodeterioration \& Biodegradation, 95, 55-60. https://doi.org/10.1016/j.ibiod.2014.05.003

[19] Nahurira, R., Ren, L. and Song, J. (2017) Degradation of di(2-ethylhexyl) Phthalate by a Novel Gordonia Alkanivorans Strain yc-rl2. Current Microbiology, 74, 1-11. https://doi.org/10.1007/s00284-016-1159-9

[20] Wu, X., Liang, R., Dai, Q., Jin, D., Wang, Y. and Chao, W. (2010) Complete Degradation of Di-n-octyl Phthalate by Biochemical Cooperation between Gordonia, sp. Strain jdc-2 and Arthrobacter, sp. Strain jdc-32 Isolated from Activated Sludge. Journal of Hazardous Materials, 176, 262-268. https://doi.org/10.1016/j.jhazmat.2009.11.022

[21] Liang, Z.F., Zhou, W., Lin, Q.Q., Yang, X.H., Wang, S.Z., Cai, X.D. and Qiu, R.L. (2014) Anaerobic Biodegradation of Phthalic Acid Esters (Paes) in Municipal Sludge. Chinese Journal of Applied Ecology, 25, 1163-1170.

[22] Wang, Y., Fan, Y. and Gu, J.-D. (2003) Degradation of Phthalic Acid and Dimethyl Phthalateby Aerobic Microorganisms. Chinese Journal of Applied \& Environmental Biology, 9, 1518-1524.

[23] Wang, H. and Lv, X.W. (2005) The Progress of the Degradation of Phthalic Acid 
Esters. Water Purification Technology, 24, 42-45.

[24] Wang, C., Xu, G.Y., Ge, C.C. and Mao, Z.Q. (2009) Progress on the Phenolic Acid Substances and Plant Soil Sickness. Northern Horticulture. 